\title{
Micromolar Brain Levels of Kynurenic Acid are Associated with a Disruption of Auditory Sensory Gating in the Rat
}

\author{
Paul D Shepard*,', Brian Joy', Lucy Clerkin', and Robert Schwarcz' \\ 'Manyland Psychiatric Research Center, Department of Psychiatry, University of Maryland School of Medicine, Baltimore, MD 21228, USA
}

\begin{abstract}
Brain levels of kynurenic acid (KYNA), an endogenous antagonist of glycine $/$ /NMDA and $\alpha-7$ nicotinic acetylcholine receptors, are elevated in individuals with schizophrenia. Both receptors are broadly implicated in the pathophysiology of this disease, particularly in the deficits many patients show in filtering the sensorium. In the present study, we sought to determine whether elevated brain levels of KYNA disrupt auditory gating in anesthetized rats. A mid-latency evoked potential was recorded from the hippocampus in response to a pair of auditory tones. Gating was assessed by determining the ratio of the amplitude of test and conditioning responses (T/C ratio) in rats that had received KYNA's precursor L-kynurenine (KYN; $150 \mathrm{mg} / \mathrm{kg}$, i.p.) together with probenecid (PBCD; $200 \mathrm{mg} / \mathrm{kg}$, i.p.) $2 \mathrm{~h}$ prior to the start of the recording session. KYNA levels in the hippocampus of KYN+PBCD-treated rats were increased 500-fold, and accompanied by a significant increase in T/C ratio consistent with a disruption in sensory gating. PBCD alone increased hippocampal KYNA I2-fold, but did not significantly elevate T/C ratio. L-70I,324 (3-30 mg/kg, i.v.), a centrally acting glycine ${ }_{B}$ site antagonist, also failed to disrupt gating; however, large quantities of the competitive NMDA receptor antagonist DL-2-amino-5-phosphopentanoate $(200 \mathrm{nmol}$, i.c.v.) markedly increased T/C ratio. Thus, while total blockade of NMDA receptors disrupts auditory gating, partial blockade achieved by antagonism of its glycine coagonist binding site does not. These observations indicate that the disruption in auditory processing in rats with greatly elevated KYNA levels is not attributable to the compound's antagonist actions at the glycine receptor. $^{2}$. Neuropsychopharmacology (2003) 28, I454-1462, advance online publication, 16 April 2003; doi: 10.1 038/sj.npp. 1300188
\end{abstract}

Keywords: sensorimotor gating; NMDA; glycine; schizophrenia; $\alpha$-7 nicotinic receptors

\section{INTRODUCTION}

Cognitive deficits have long been considered a core feature of schizophrenia. The failure of antipsychotic drugs to reverse these symptoms and their disproportionate impact on quality of life has led to a sustained effort to discover their neurobiological underpinnings (Buchanan et al, 1994, 1998). It has long been assumed that a reduction in the brain's capacity to filter irrelevant information from the sensorium contributes to these impairments (McGhie and Chapman, 1961; Venables, 1964). Indeed, individuals with schizophrenia exhibit pronounced deficits in psychophysiological measures of sensory gating. In one such paradigm, a pair of identical acoustic tones is presented during acquisition of electroencephalographic activity. Epochs of the recording bracketing the stimuli are averaged to generate a pair of event-related potentials (ERPs). When stimuli are applied in close succession, the amplitude of the

* Correspondence: Dr PD Shepard, Maryland Psychiatric Research, P.O. Box 21247, Baltimore, MD 21228, USA, Tel: + I 4I0 402 7753, Fax: + I 410402 6066, E-mail: pshepard@mprc.umaryland.edu Received 09 January 2003; accepted 05 February 2003

Online publication: 26 February 2003 at http://www.acnp.org/citations/ Npp0226030 I4/default.pdf
ERP elicited by the first or conditioning stimulus exceeds the response evoked by the second or test stimulus, often by a factor of two or more. The diminished response to the second tone is thought to reflect the neural processes involved in gating sensory input and is typically quantified as the ratio of test to conditioning (T/C) response amplitude (Adler et al, 1999; Light and Braff, 1999). Numerous studies have demonstrated that persons with schizophrenia exhibit a blunted response to conditioning stimuli and a failure to show the characteristic reduction in ERP amplitude to the test stimulus (Adler et al, 1982; Boutros et al, 1991; Jin et al, 1997; Clementz et al, 1998a,b; Patterson et al, 2000). Notably, these deficits are strongly correlated with neuropsychological measures of attention (Erwin et al, 1998) and vigilance (Cullum et al, 1993). Abnormalities in sensory gating have been detected in unaffected family members of individuals with schizophrenia and in patients afflicted with schizotypal personality disorder, suggesting that anomalous sensory gating may represent an intermediate phenotypic marker of the illness (Siegel et al, 1984; Waldo et al, 1991; Clementz et al, 1998b; Cadenhead et al, 2000).

In addition to their role in clinical research, auditory ERP recording techniques are readily adapted for use in laboratory animals including the anesthetized rat. This preparation has been particularly valuable for studying the 
neurobiological basis of auditory gating. Results from a number of these studies have implicated both glutamatergic and cholinergic mechanisms in this phenomenon. Animals acutely administered the noncompetitive NMDA receptor antagonists, phencyclidine or dizolcipine (MK-801), exhibit deficits in auditory sensory gating that are qualitatively similar to those observed in schizophrenia (Adler et al, 1986; Miller et al, 1992a). Removal of hippocampal cholinergic afferents or administration of $\alpha-7$ nicotinic acetylcholine receptor $(\alpha 7 \mathrm{nAChR})$ antagonists also disrupts auditory gating (Luntz-Leybman et al, 1992; Bickford and Wear, 1995). These data, together with clinical studies identifying a genetic linkage between auditory gating deficits in schizophrenic patients and the $\alpha 7 \mathrm{nAChR}$ (Freedman et al, 1997), suggest that cholinergic neurons are an important and highly conserved component of the auditory gating pathway.

Although the neurobiological basis of sensory gating deficits in schizophrenia remains unknown, convergent lines of evidence suggest that glutamatergic and/or cholinergic neurotransmission is abnormally depressed. One possibility is that these impairments are related to an increase in brain levels of endogenous neuroactive compounds that modulate the activity of these neurotransmitters or their receptors. Brain and cerebrospinal fluid (CSF) levels of one such candidate, kynurenic acid (KYNA), a tryptophan metabolite and endogenous excitatory amino acid (EAA) receptor antagonist, are elevated in schizophrenic patients (Erhardt et al, 2001; Schwarcz et al, 2001). In addition to its well-characterized action as a competitive antagonist of the glycine coagonist binding site (glycine ${ }_{B}$ site) on the NMDA receptor, KYNA also functions as a noncompetitive antagonist of the $\alpha 7 \mathrm{nAChR}$ (Hilmas et al, 2001). Indeed, KYNA exhibits higher affinity for the $\alpha 7 \mathrm{nAChR}$ than for the glycine $_{\mathrm{B}}$ site, suggesting that $\alpha 7 n A C h R$ blockade may account for some actions that had been previously ascribed exclusively to blockade of ionotropic EAA receptors.

In the present series of experiments, electrophysiological techniques were used to determine the effects of increased endogenous KYNA levels on auditory gating in the anesthetized rat. To accomplish this, L-kynurenine (KYN), the immediate precursor of KYNA, was administered together with probenecid (PBCD), an antagonist of organic acid transport (Miller and Ross, 1976; Suzuki et al, 1987). Experiments were also conducted comparing the effects of a centrally acting glycine ${ }_{B}$ site antagonist (L-701, 324) with DL-2-amino-5-phosphopentanoate (DL-APV), a prototypical competitive antagonist of the glutamate binding site on the NMDA receptor. Our results indicate that while elevated brain levels of KYNA are capable of disrupting auditory processing, these effects are not due to competitive blockade of the glycine ${ }_{\mathrm{B}}$ site. A preliminary account of these results has been published in abstract form (Clerkin et al, 2001).

\section{MATERIALS AND METHODS}

\section{Animals}

All studies were conducted using adult, male SpragueDawley rats (300-500 g) obtained from Charles River
Laboratories (Wilmington, MA). Animals were housed in a temperature-controlled vivarium under scheduled lighting conditions and were provided unrestricted access to food and water. All experiments were conducted in strict accordance with the procedures outlined in the Guide for the Care and Use of Laboratory Animals (http://oacu.od. nih.gov/regs/guide/guidex.htm) and with the approval of the Institutional Animal Care and Use Committee of the University of Maryland School of Medicine.

\section{Drugs}

L-Kynurenine sulfate and probenecid (Sigma, St Louis, MO) were dissolved in $2 \mathrm{~N} \mathrm{NaOH}$ and diluted to a final concentration of $30 \mathrm{mg} / \mathrm{ml}$ with $0.1 \mathrm{M}$ HEPES buffer. Both solutions were adjusted to a final $\mathrm{pH}$ of 8.4 with $2 \mathrm{~N} \mathrm{NaOH}$ or $1 \mathrm{~N} \mathrm{HCl}$. L-701,324 (7-chloro-4-hydroxy-3-(3-phenoxy)phenyl-2(H)-quinolinone; Tocris, Ballwin, MO) was suspended in $20 \%$ polyethylene glycol and adjusted to $\mathrm{pH} 10$ with $0.5 \mathrm{~N} \mathrm{HCl}$. Drugs were prepared fresh daily and stored at $4^{\circ} \mathrm{C}$ in amber bottles. DL-APV was dissolved in a few drops of $1 \mathrm{~N} \mathrm{NaOH}$ and diluted to a final concentration of $40 \mathrm{mM}$ in $0.9 \%$ saline $(\mathrm{pH}=7)$. Vehicle solutions were prepared from the same solvents used to dissolve the active drug and adjusted to a comparable $\mathrm{pH}$.

\section{Evoked Potential Recording}

Animals were anesthetized with chloral hydrate $(400 \mathrm{mg} / \mathrm{kg}$, i.p.) and mounted in a stereotaxic frame with hollow, atraumatic ear bars. Body temperature was maintained at $36.5^{\circ} \mathrm{C}$ using a feedback-controlled heating pad. A burr hole was drilled in the skull to permit placement of an epoxycoated tungsten microelectrode (FHC, Bowdoinham, ME, $10 \mathrm{M} \Omega$ at $135 \mathrm{~Hz}$ ) in the CA3 region of the hippocampus (3.8 $\mathrm{mm}$ posterior to bregma; $3.8 \mathrm{~mm}$ lateral to midline; 2.8 $3.2 \mathrm{~mm}$ ventral to cortical surface; Paxinos and Watson, 1986). CA3 pyramidal neurons were identified by their characteristic pattern of discharge (Ranck, 1973; Bickford and Wear, 1995). Electrode potentials were amplified, filtered $(0.01-1 \mathrm{kHz})$, digitized, and viewed in real time using Axoscope (Axon Instruments, Union City, CA). Auditory stimuli, consisting of two $3 \mathrm{kHz}$ tones $(10 \mathrm{~ms}$ duration), were digitally generated (Wavetek, Norfolk, UK) and amplified using a conventional stereo amplifier. The output of the audio amplifier was directed to a pair of insert earphones (Etymotic Research, Elk Grove Village, IL). Tone pairs were delivered binaurally via the ear bars every $10 \mathrm{~s}$ with an interstimulus interval of $500 \mathrm{~ms}$. Recordings were digitized in $1 \mathrm{~s}$ epochs beginning $100 \mathrm{~ms}$ before presentation of the first stimulus and stored to disk as separate trials. Responses to 16 consecutive tone pairs (subsequently referred to as one 'episode') were averaged to generate a waveform for analysis. The N40 component of the auditory evoked potential was identified as the largest negativity occurring 30-60 ms after stimulus onset. Its amplitude was measured relative to the largest preceding positivity occurring at least $10 \mathrm{~ms}$ after stimulus onset. Gating was expressed as the ratio of the amplitude of the second (test) response to the first (conditioning) response, and $\mathrm{T} / \mathrm{C}$ ratios were computed for each episode. In two animals per treatment group, the recording site was marked by passing a 
small DC current $(20 \mu \mathrm{A}$ for $3 \mathrm{~min})$ through the tip of the electrode. These animals were deeply anesthetized and perfused transcardially with saline followed by $10 \%$ neutral buffered formalin. Coronal sections $(50 \mu \mathrm{m})$ were cut on a freezing microtome, counterstained with cresyl violet, and examined microscopically. All lesions were localized within the $\mathrm{CA} 3$ region of the hippocampus.

\section{Biochemical Determinations}

In the first group of experiments, tissue levels of $\mathrm{KYN}$, KYNA and quinolinic acid (QUIN) in the hippocampus were measured in six animals per treatment group. Animals were killed by decapitation immediately after the recording session. Brains were rapidly removed, frozen on dry ice, and stored at $-80^{\circ} \mathrm{C}$ until the day of the assay. The hippocampus was dissected out, and the tissue was sonicated $(1: 10$, $\mathrm{w} / \mathrm{v}$, in ultrapure water) and acidified with $6 \% \mathrm{HClO}_{4}$.

After centrifugation ( $5 \mathrm{~min}$ ), an aliquot of the supernatant was diluted in $0.2 \mathrm{M}$ zinc acetate containing $5 \%$ acetonitrile ( $\mathrm{pH}$ 6.2). KYN levels were determined by HPLC analysis with UV detection at $365 \mathrm{~nm}$. For the measurement of KYNA, samples were subjected to HPLC analysis with fluorescence detection (excitation wavelength: $344 \mathrm{~nm}$; emission wavelength: $398 \mathrm{~nm}$ ) (Wu et al, 2000a).

QUIN levels were assayed by mass spectroscopy using an aliquot of the tissue homogenate used for the determination of KYN and KYNA. The homogenate was further diluted $(1: 2.5, \mathrm{v} / \mathrm{v}$, in ultrapure water). Samples were prepared by adding $50 \mu \mathrm{l}$ of an internal standard (pyridine-3,5-dicarboxylic acid, Sigma) to $50 \mu \mathrm{l}$ of this homogenate, and $25 \mu \mathrm{l}$ of $5 \mathrm{~N} \mathrm{HCl}$ and $125 \mu \mathrm{l}$ chloroform were added to eliminate fatty acids. After centrifugation in a microfuge (15 $\mathrm{min})$, the supernatant was added to $125 \mu \mathrm{l}$ of $50 \mathrm{mM}$ tetrabutylammonium sulfate and lyophilized overnight. The lyophilized material was resuspended in acetonitrile containing diisopropylethylamine and pentafluorobenzylbromide (PFB). After incubation at $60-65^{\circ} \mathrm{C}, 25 \mu \mathrm{l}$ of decane and $750 \mu \mathrm{l}$ of water were added, and the mixture was centrifuged in a microfuge $(15 \mathrm{~min})$. In all, $20 \mu \mathrm{l}$ of the decane phase was removed, and $1 \mu \mathrm{l}$ was subjected to GC/MS analysis. Spectrographic analysis was performed using a trace gas chromatographer coupled to a quadrupole mass spectrometer (CG/ECNI-MS, ThermoFinnigan, San Jose, CA). Chromatographic separation was performed using a capillary column $(0.25 \mathrm{~mm}$ i.d., film thickness $0.25 \mu \mathrm{m}, 30 \mathrm{~m}$ DB$5 \mathrm{~ms}$, J\&W Scientific, Folsom, CA) with helium as the carrier gas. The temperature was programmed as follows: $155^{\circ} \mathrm{C}$ for $1.25 \mathrm{~min}, 40^{\circ} \mathrm{C} / \mathrm{min}$ to $270^{\circ} \mathrm{C}, 10^{\circ} \mathrm{C} / \mathrm{min}$ to $320^{\circ} \mathrm{C}, 1 \mathrm{~min}$ at $320^{\circ} \mathrm{C}$, injection port at $228^{\circ} \mathrm{C}$. The ion source temperature was $220^{\circ} \mathrm{C}$. Selected ion monitoring analyses were performed by recording signals of characteristic (M-PFB) ions. The $m / z$ value for (QUIN-PFB) ${ }^{-}$is 346 .

Tissue concentrations of KYN, KYNA, and QUIN were compared between treatment groups using the KruskalWallis ANOVA on ranks and Dunnett's post hoc method without adjustment for ties.

\section{Experimental Design}

Experiment 1: effect of elevated KYNA levels on N40 auditory gating. In these experiments, brain levels of KYNA were elevated by blocking organic acid transport with $\mathrm{PBCD}$ or by jointly administering PBCD and KYNA's bioprecursor KYN. Based on previous studies, we anticipated that KYNA levels would peak approximately $2 \mathrm{~h}$ after systemic administration of these compounds (Miller et al, 1992b; Vécsei et al, 1992). The prolonged post-treatment interval precluded the use of a repeated measures design. Accordingly, we adopted a parallel groups approach in which 32 animals were randomly assigned to one of four treatment groups including naïve, vehicle, PBCD $(200 \mathrm{mg} / \mathrm{kg})$, or PBCD $(200 \mathrm{mg} / \mathrm{kg})+\mathrm{KYN}(150 \mathrm{mg} / \mathrm{kg})(n=8$ per group). Vehicle or drugs were injected i.p. 60 min prior to administration of chloral hydrate, and recordings began $2 \mathrm{~h}$ after the drugs had been administered. Five consecutive episodes, each comprised of the average response to 16 stimulus trials, were acquired over a 20 -min interval. The amplitudes of the conditioning and test waveforms (in $\mu \mathrm{V}$ ) were used to determine the $\mathrm{T} / \mathrm{C}$ ratio for each episode. Data from all five episodes were averaged to create a mean response for each animal. Grand means, representing the average response of subjects within each treatment group, were compared using a one-way analysis of variance (ANOVA). Post hoc pairwise comparisons were performed using a Bonferroni $t$-test. Individuals conducting these experiments remained unaware of the treatment condition of the animals until all of the data had been analyzed.

In addition to comparing the mean $\mathrm{T} / \mathrm{C}$ ratio between treatment groups, we determined the frequency of occurrence of abnormal episodes in control and drug-treated rats. In accordance with previous studies (Adler et al, 1986; Miller et al, 1992a, 1995), T/C ratios $>0.5$ were operationally defined as abnormal. Between-group comparisons were made using the Savage or log rank test (Lehman, 1974). Pvalues were calculated by a permutation procedure (SAS ${ }^{\circledR}$ PROC NPAR1WAY, SAS Institute, 1997) rather than relying on the asymptotic $\chi^{2}$ distribution of the Savage statistic. In an effort to reduce Type I error rate, the closed testing procedure of Marcus et al (1976) was used. Accordingly, if the global null hypothesis was rejected at $P<0.05$ (distribution of abnormal counts same in all groups), a pairwise null hypothesis of the form Group $A=$ Group $B$ would be rejected at $P<0.05$ only if the three-way hypotheses (Group $\mathrm{A}=\mathrm{B}=\mathrm{C}$ and Group $\mathrm{A}=\mathrm{B}=\mathrm{D}$ ) were also rejected at $P<0.05$. All hypothesis tests were two-sided.

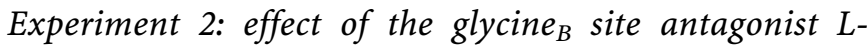
701,324 on $N 40$ auditory gating. Dose-response studies were performed to assess the effects of L-701,324, a centrally acting glycine $\mathrm{B}_{\mathrm{B}}$ antagonist, on auditory sensory gating. Rats $(n=23)$ were prepared for recording as described above with the addition of a cannula that was surgically implanted in the femoral vein. Two consecutive episodes were recorded to establish the baseline gating status of each animal. Only those animals that exhibited normal gating characteristics $(\mathrm{T} / \mathrm{C}$ ratio $<0.5)$ were selected for further study. At $5 \mathrm{~min}$ after the last baseline recording, animals received one of three doses of L-701,324 $(3,10$, or $30 \mathrm{mg} /$ $\mathrm{kg}$ ), or an equivalent volume of vehicle using an infusion pump programmed to inject the solutions at a rate of $0.2 \mathrm{ml} /$ min. Evoked potential recordings were acquired in $5 \mathrm{~min}$ intervals beginning $10 \mathrm{~min}$ prior to drug infusion and continuing for $55 \mathrm{~min}$. Data were smoothed by averaging 
the conditioning and test response amplitudes obtained from two consecutive episodes. T/C ratios generated from these data were plotted in $10 \mathrm{~min}$ intervals. Differences between group means were evaluated using a two-way repeated measures analysis of variance (RMANOVA).

Experiment 3: effects of the competitive NMDA receptor antagonist $D L-A P V$ on $N 40$ auditory gating. The effects of competitive blockade of the glutamate binding site on auditory gating was studied by comparing T/C ratios obtained before and after intracerebroventricular (i.c.v.) injection of DL-APV. Rats $(n=12)$ were prepared for recording as described earlier. An additional burr hole was drilled in the skull, and a stainless steel cannula was lowered into the lateral ventricle for drug administration $(0.8 \mathrm{~mm}$ posterior to bregma, $1.2 \mathrm{~mm}$ lateral, $3.5 \mathrm{~mm}$ ventral; Paxinos and Watson, 1986). Injections were made ipsilateral to the recording electrode. Two consecutive episodes were recorded under baseline (preinjection) conditions. Animals that failed to gate normally (T/C ratio 0.5 ) were not tested further. At $5 \mathrm{~min}$ after acquisition of the second baseline episode, animals received $5 \mu \mathrm{l}$ of DL-APV $(40 \mathrm{mM})$ or vehicle $(0.9 \%$ saline $)$. Solutions were delivered at a rate of $1 \mu \mathrm{l} / \mathrm{min}$. Recordings began immediately following the injection and continued in $5 \mathrm{~min}$ intervals for the next $45 \mathrm{~min}$. As in the previous group of experiments, data were smoothed by averaging two consecutive episodes. Differences between treatment groups were evaluated using a two-way RMANOVA.

\section{RESULTS}

\section{Experiment 1: Effect of Elevated KYNA Levels on N40 Auditory Gating}

Peripheral KYN loading together with blockade of organic acid transport proved to be an effective strategy for increasing tissue levels of KYNA in the CNS (Table 1). KYNA levels in the hippocampus of untreated rats ranged from 20 to $60 \mathrm{nM}$ and did not differ from the vehicle-treated group. Brain levels of KYN were also unaffected by vehicle treatment. PBCD $(200 \mathrm{mg} / \mathrm{kg})$ increased tissue levels of KYN and KYNA by 4- and 12-fold, respectively, whereas QUIN levels remained unchanged. Coadministration of $\mathrm{KYN}$ $(150 \mathrm{mg} / \mathrm{kg})$ and $\mathrm{PBCD}$ resulted in a 215 -fold increase in the concentration of KYN in the hippocampus. The increased availability of the substrate together with block-

Table I Effects of PBCD $(200 \mathrm{mg} / \mathrm{kg})$ with and without KYN ( $150 \mathrm{mg} / \mathrm{kg}$ ) on the Tissue Concentration of KYN, KYNA, and QUIN in the Rat Hippocampus

\begin{tabular}{lccc}
\hline Treatment & $\begin{array}{c}\text { KYN } \\
(\boldsymbol{\mu M})\end{array}$ & $\begin{array}{c}\text { KYNA } \\
(\mathbf{n M})\end{array}$ & $\begin{array}{c}\text { QUIN } \\
(\mathbf{n M})\end{array}$ \\
\hline Naïve & $0.9 \pm 0.1$ & $40 \pm 6$ & $92 \pm 5$ \\
Vehicle & $1.0 \pm 0.1$ & $36 \pm 3$ & $71 \pm 4$ \\
PBCD & $3.8 \pm 0.3^{*}$ & $479 \pm 48$ & $70 \pm 4$ \\
KYN+PBCD & $193.0 \pm 20.0^{*}$ & $20 \pm 2 \mu M^{*}$ & $220 \pm 26$ \\
\hline
\end{tabular}

Drugs were administered 150 min before sacrifice. Data are presented as the mean \pm SEM of six rats per group. $* P<0.05$ compared to uninjected controls, Dunnett's method without adjustment for ties. ade of organic acid transport also resulted in a significant increase in hippocampal KYNA levels, which reached $20 \mu \mathrm{M}$ $2.5 \mathrm{~h}$ after drug treatment. QUIN levels in the hippocampus of KYN + PBCD-treated rats were not different from naïve animals.

Mean T/C ratios obtained from animals in each of the four treatment groups are illustrated in Figure 1. Naïve animals showed the smallest average $\mathrm{T} / \mathrm{C}$ ratio $(0.31 \pm 0.04)$, indicative of a strong attenuation in the response evoked by the second of two auditory stimuli. Vehicle-injected controls and PBCD-treated rats showed comparable responses $(0.39 \pm 0.07$ and $0.40 \pm 0.08$, respectively). Animals that received KYN together with PBCD exhibited a marked elevation in $\mathrm{T} / \mathrm{C}$ ratio $(0.64 \pm 0.10)$. This fulfilled the criteria used to operationally define abnormal gating (i.e. $\mathrm{T} / \mathrm{C}>0.5$ ) and differed significantly from naïve controls (ANOVA $\mathrm{F}_{(3,28)}=3.6, P=0.025$; Bonferroni $t=3.1 ; P<0.02)$.

The individual $\mathrm{T} / \mathrm{C}$ ratios used to compile the grand means presented in Figure 1 represent the average of five consecutive episodes acquired over a 20-min interval immediately preceding sacrifice. This approach was adopted to reduce the possibility of an aberrant episode making a disproportionate contribution to the results. It also enabled us to compare the frequency of normal and abnormal trials among the subjects in each treatment group (Table 2). Naïve animals exhibited the fewest number of abnormal trials. Individual $\mathrm{T} / \mathrm{C}$ ratios exceeded 0.5 in only six of the 40 episodes recorded ( 8 animals $\times 5$ episodes/ animal), and none of the naive animals exhibited more than two abnormal episodes. Vehicle- and PBCD-treated rats showed a modest increase in the number of abnormal episodes, but these differences did not reach statistical significance. The highest incidence of abnormal trials was observed in the KYN + PBCD group in which the T/C ratio

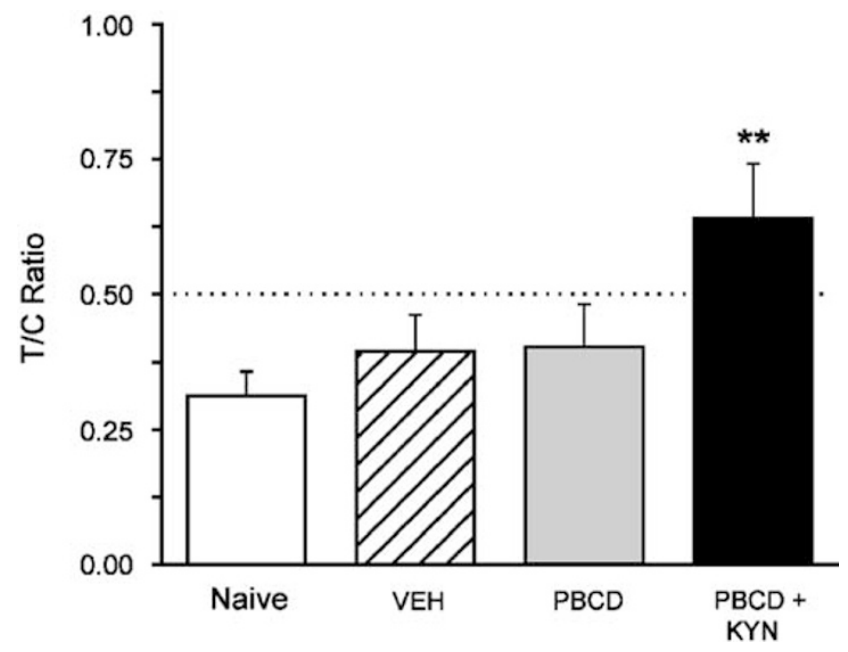

Figure I Effects of $P B C D$ and $K Y N$ on auditory gating in the anesthetized rat. Data represent the mean \pm SEM T/C ratio obtained from naiive rats and animals that received an i.p. injection of vehicle (VEH), PBCD $(200 \mathrm{mg} / \mathrm{kg})$, or PBCD + KYN (I50 mg/kg) (eight animals per group). Values were acquired over a 20-min interval beginning $120 \mathrm{~min}$ after drug or vehicle treatment. T/C ratios above 0.5 (dashed line) denote disrupted sensory gating. $* * P<0.015$ compared to naive animals, Bonferroni t-test. 
Table 2 Distribution of Abnormal Episodes ( $T / C>0.5)$ by Treatment Group

\begin{tabular}{|c|c|c|c|c|c|c|c|c|}
\hline \multirow[b]{2}{*}{$\begin{array}{l}\text { No. of abnormal } \\
\text { episodes }\end{array}$} & \multicolumn{2}{|c|}{ KYN/PBCD } & \multicolumn{2}{|c|}{ VEH/PBCD } & \multicolumn{2}{|c|}{ VEH/VEH } & \multicolumn{2}{|c|}{ Naïve } \\
\hline & $n$ & $\%$ & $n$ & $\%$ & $n$ & $\%$ & $n$ & $\%$ \\
\hline 0 & I & 12.5 & 3 & 37.5 & 3 & 37.5 & 4 & 50.0 \\
\hline I & 2 & 25.0 & 2 & 25.0 & 2 & 25.0 & 2 & 25.0 \\
\hline 2 & 0 & 0.0 & I & 12.5 & 2 & 25.0 & 2 & 25.0 \\
\hline 3 & 3 & 37.5 & 2 & 25.0 & 1 & 12.5 & 0 & 0.0 \\
\hline 4 & 2 & 25.0 & 0 & 0.0 & 0 & 0.0 & 0 & 0.0 \\
\hline $\begin{array}{l}\text { Abnormal } \\
\text { episodes/rat }\end{array}$ & \multicolumn{2}{|c|}{$2.38 \pm 0.53^{*}$} & \multicolumn{2}{|c|}{$1.25 \pm 0.45$} & \multicolumn{2}{|c|}{$1.13 \pm 0.40$} & \multicolumn{2}{|c|}{$0.75 \pm 0.31$} \\
\hline
\end{tabular}

Global Savage test for differences: $\chi^{2}=8.68, \mathrm{df}=3$, permutation $P$-value $=$ 0.022 . *KYN/PBCD vs naïve, $\chi^{2}=4.88$, permutation $P$-value $=0.018$.

exceeded 0.5 in nearly half of the episodes. Five of the eight animals tested exhibited three or more abnormal episodes. As a group, these animals exhibited a significantly greater proportion of abnormal episodes than uninjected controls $\left(\chi^{2}=4.9, P=0.018\right)$.

\section{Experiment 2: Effect of the Glycine ${ }_{B}$ Site Antagonist L-701,324 on N40 Auditory Gating}

The disruption in auditory gating observed in animals with elevated brain levels of KYNA prompted us to assess the effects of L-701,324, a centrally acting glycine $_{B}$ site antagonist. Rats received a bolus injection of one of three doses of the drug $(3,10$, or $30 \mathrm{mg} / \mathrm{kg})$ administered intravenously to facilitate entry into the brain (Murray et al, 2000). The results of these experiments are illustrated in Figure 2. All rats exhibited normal gating ( $\mathrm{T} / \mathrm{C}$ ratio $<0.5)$ prior to drug injection. RMANOVA revealed main effects for both dose $\left(\mathrm{F}_{(3,95)}=3.3, P<0.05\right)$ and time $\left(\mathrm{F}_{(5,95)}=4.5, P<0.001\right)$. However, there was no evidence of a dose $\times$ time interaction, indicating that none of the three doses of L-701,324 differed from one another at any of the intervals sampled.

\section{Experiment 3: Effects of the Competitive NMDA Receptor Antagonist DL-APV on N40 Auditory Gating}

The effects of $200 \mathrm{nmol}$ DL-APV on N40 auditory gating are illustrated in Figure 3. Omnibus testing revealed main effects for treatment $\left(\mathrm{F}_{(1,50)}=7.9, \quad P<0.05\right)$, time $\left(\mathrm{F}_{(5,50)}=4.6, \quad P<0.005\right)$, and their interaction (treatment $\times$ time: $\left.\mathrm{F}_{(5,50)}=4.8, P<0.001\right)$. The average $\mathrm{T} / \mathrm{C}$ ratio obtained from vehicle-treated rats remained below 0.5 for the duration of the experiment and showed no evidence of a change over time. By contrast, animals treated with DL-APV exhibited a time-dependent increase in $\mathrm{T} / \mathrm{C}$ ratio that exceeded 0.5 within $15 \mathrm{~min}$ after injection. Significant differences were observed between drug- and vehicletreated animals beginning 20-25 min following administration and persisted for the duration of the experiment. Comparison of the relative contribution made by test and conditioning waveforms revealed that the increase in $\mathrm{T} / \mathrm{C}$ ratio was due entirely to a decrease in the conditioning response amplitude (Table 3 ).

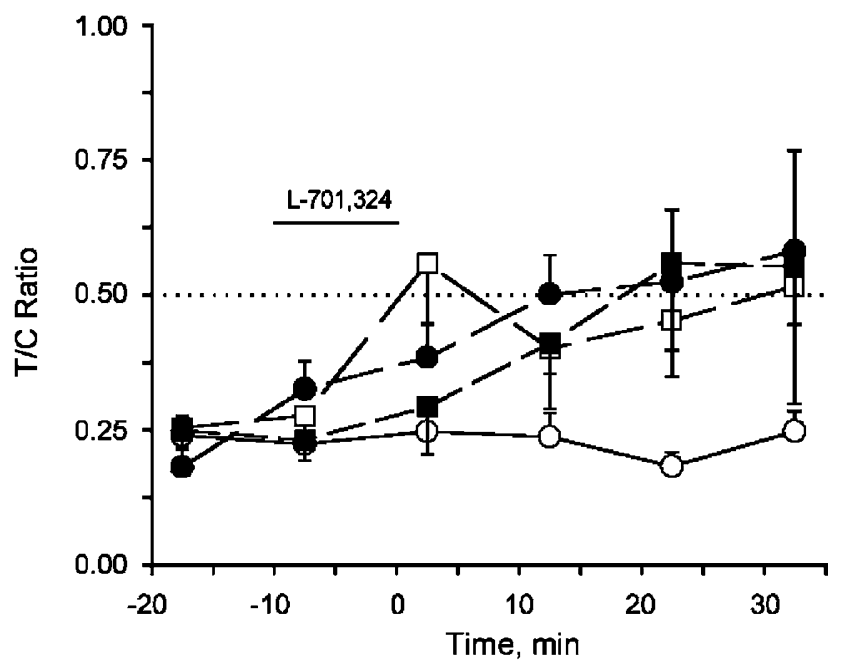

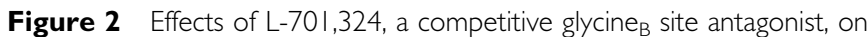
auditory gating in the anesthetized rat. Data represent the T/C ratio (mean \pm SEM) of animals that received an injection of vehicle $(n=5$, open circles) or one of three doses of L-701,324 (3 mg/ $/ \mathrm{kg}, n=7$, open rectangles; $10 \mathrm{mg} / \mathrm{kg}, n=6$, filled circles; $30 \mathrm{mg} / \mathrm{kg}, n=5$, filled rectangles). Solutions were injected intravenously during the interval denoted by the solid horizontal line.

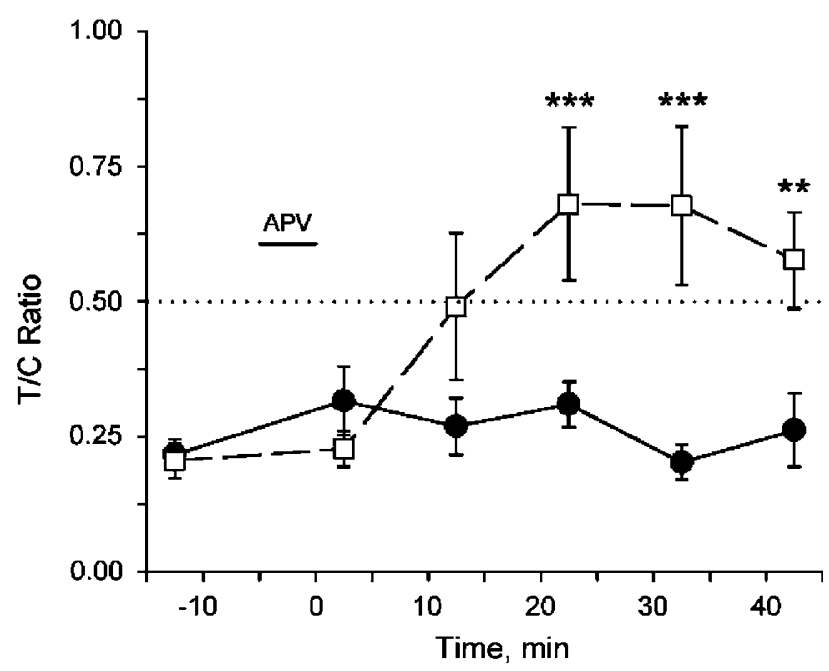

Figure 3 Effect of DL-APV, a competitive NMDA receptor antagonist on auditory gating in the anesthetized rat. Data represent the T/C ratio (mean \pm SEM) of animals that received an i.c.v. injection of $5 \mu$ vehicle ( $n=6$, filled circles) or $200 \mathrm{nmol}$ DL-APV ( $n=6$, open squares). The solid horizontal line denotes duration of the injection. ${ }^{*} * P<0.0$ I, *** $P<0.00$ I compared to baseline (-12.5 min) using a two-tailed Bonferroni t-test.

\section{DISCUSSION}

Neuroactive metabolites of tryptophan along the kynurenine pathway have been implicated in a variety of neurological and psychiatric diseases including Huntington's and Parkinson's disease, stroke, epilepsy and schizophrenia (Stone, 2001; Schwarcz and Pellicciari, 2002). In the brain, both QUIN and KYNA are derived from KYN, which enters the CNS via the same carrier system as tryptophan (Fukui et al, 1991; Guidetti et al, 1995). However, unlike tryptophan, which serves as a substrate for serotonin biosynthesis in neurons, brain $\mathrm{KYN}$ is preferentially 
Table 3 Conditioning and Test Response Amplitudes Before and After i.c.V. Infusion of DL-APV

\begin{tabular}{lccccc}
\hline & \multicolumn{2}{c}{$\begin{array}{c}\text { Conditioning response } \\
\text { amplitude }(\boldsymbol{\mu V})\end{array}$} & & \multicolumn{2}{c}{$\begin{array}{c}\text { Test response } \\
\text { amplitude }(\boldsymbol{\mu} \mathbf{V})\end{array}$} \\
\cline { 2 - 3 } \cline { 6 - 7 } $\begin{array}{l}\text { Injection } \\
\text { interval (min) }\end{array}$ & Vehicle & APV & & Vehicle & APV \\
\hline-12.5 & $232 \pm 28$ & $248 \pm 31$ & & $48 \pm 5$ & $49 \pm 7$ \\
2.5 & $231 \pm 25$ & $153 \pm 19 * *$ & & $69 \pm 13$ & $33 \pm 4$ \\
12.5 & $250 \pm 26$ & $96 \pm 18^{* * * * *}$ & & $62 \pm 9$ & $37 \pm 8$ \\
22.5 & $260 \pm 20$ & $70 \pm 17 * * *$ & & $78 \pm 11$ & $37 \pm 6$ \\
32.5 & $247 \pm 18$ & $81 \pm 19 * * *$ & & $48 \pm 5$ & $51 \pm 13$ \\
42.5 & $228 \pm 26$ & $104 \pm 26 * * *$ & & $54 \pm 9$ & $51 \pm 6$ \\
\hline
\end{tabular}

Data represent mean \pm SEM of six rats per group. ${ }^{*} * P<0.01$, **** $P<0.001$

compared to baseline (-12.5 min) values using a two-tailed Bonferroni t-test.

metabolized in astrocytes and microglial cells. Accordingly, these cells serve as the primary source of QUIN and KYNA in the brain (Guillemin et al, 2001; Schwarcz and Pellicciari, 2002). To date, most hypotheses involving the kynurenine pathway have emphasized the potential pathophysiological significance of elevations in brain QUIN, a potent excitotoxin and NMDA receptor agonist (Stone, 2001). Comparatively less attention has been paid to the possible pathogenic role of KYNA, a compound with significant anticonvulsant and neuroprotective properties (Schwarcz et al, 1992). KYNA is the end product in a side arm of the kynurenine pathway, and its formation is regulated by a number of distinct and, in some cases, brain-specific mechanisms (Gramsbergen et al, 1997; Hodgkins and Schwarcz, 1998). Changes in brain KYNA levels including those observed in schizophrenia, may be caused by impairment in one or more of these processes. Since KYNA cannot be cleared by cellular reuptake or enzymatic degradation, efflux through a nonspecific, $\mathrm{PBCD}$-sensitive organic acid transporter appears to be the major mode of its elimination from the brain (Moroni et al, 1988; Turski and Schwarcz, 1988).

In the present study, we sought to test the premise that elevated brain levels of KYNA, an antagonist of both the glycine $_{B}$ site on the NMDA receptor and the $\alpha 7 \mathrm{nAChR}$, would produce a deficit in auditory sensory gating. Our hypothesis was based on evidence implicating glutamatergic and cholinergic receptors in sensory gating (Adler et al, 1986; Luntz-Leybman et al, 1992; Miller et al, 1992a; Bickford and Wear, 1995) and on data showing that cortical and CSF KYNA levels are elevated in schizophrenia (Erhardt et al, 2001; Schwarcz et al, 2001), a disorder characterized by marked auditory gating deficits (Adler et al, 1982; Boutros et al, 1991; Jin et al, 1997; Clementz et al, 1998a, b; Patterson et al, 2000). Since KYNA penetrates the bloodbrain barrier very poorly (Fukui et al, 1991), an indirect approach was implemented, involving blockade of the PBCD-sensitive transporter alone and in conjunction with the administration of KYNA's immediate bioprecursor KYN. In accordance with previously published data, PBCD alone elevated hippocampal KYNA levels 12-fold (Miller et al, 1992b; Vécsei et al, 1992). As an inhibitor of the transport of all organic acids across epithelial barriers, PBCD also increases brain levels of several other compounds, including acidic products of indole and catecho- lamine degradation. In addition, PBCD causes nonspecific changes in brain chemistry, for example an increase in KYN levels (Table 1; cf also Vécsei et al, 1992). However, neither of these PBCD-induced effects were sufficient to modify auditory gating. By contrast, the 500-fold increase in hippocampal KYNA levels produced by $\mathrm{PBCD}+\mathrm{KYN}$, which occurred in the absence of changes in brain QUIN, significantly increased the $\mathrm{T} / \mathrm{C}$ ratio in a manner that is typically interpreted as reflecting a disruption in sensory gating.

The most parsimonious interpretation of these data is that KYNA-mediated blockade of the glycine ${ }_{\mathrm{B}}$ site $\left(\mathrm{IC}_{50}\right.$ : 10$15 \mu \mathrm{M}$; Birch et al, 1988a, b; Kessler et al, 1989; Danysz et al, 1989 ) is responsible for the observed deficit in auditory gating. This notion would be consistent with the fact that KYNA levels comparable to those attained in the present study are capable of blocking the convulsant and excitotoxic effects of NMDA receptor agonists (Vécsei et al, 1992; Santamaria et al, 1996). Similar antiexcitotoxic effects can be achieved by several specific glycine ${ }_{B}$ site antagonists (Leeson and Iversen, 1994; Danysz and Parsons, 1998). In an effort to assess the role of glycine ${ }_{B}$ receptor blockade on auditory gating, we tested the effect of L-701,324, a specific, centrally acting glycine $\mathrm{B}_{\mathrm{B}}$ site antagonist (Bristow et al, 1996a, b; Grimwood et al, 1995). Although previous studies had shown that a single dose of $6 \mathrm{mg} / \mathrm{kg}$ (i.p.) results in behavioral changes indicative of NMDA receptor blockade (Bristow et al, 1996a, b), this dose had no effect on auditory gating (Clerkin et al, 2001). Subsequent studies were conducted using an intravenous route of administration to increase the drug's access to the brain. The doses of L701,324 selected for testing exhibit widely divergent effects on $\left[{ }^{3} \mathrm{H}\right] \mathrm{MK}-801$ binding in vivo, ranging from $<10 \%$ inhibition at $3 \mathrm{mg} / \mathrm{kg}$ to $>80 \%$ inhibition at $30 \mathrm{mg} / \mathrm{kg}$ (Murray et al, 2000). At all doses tested, a nonsignificant trend toward an increase in T/C ratio was observed but there was no evidence of a dose dependency of the response. Further evidence for a dissociation between glycine $_{B}$ receptor blockade and auditory gating mechanisms was provided by studies in which the selective glycine ${ }_{B}$ receptor antagonist 7-chlorokynurenic acid $\left(\mathrm{IC}_{50}: 0.56 \mu \mathrm{M}\right.$; Leeson and Iversen, 1994) was produced in situ following the i.p. administration of its precursor 4-chlorokynurenine ( $\mathrm{Wu}$ et al, 2000b) and PBCD. These experiments, which were designed and performed in analogy to the studies described in this communication, showed that hippocampal 7chlorokynurenic acid levels in excess of $4.5 \mu \mathrm{M}$ had no effect on auditory gating (manuscript in preparation).

In contrast to glycine ${ }_{\mathrm{B}}$ receptor blockade, i.c.v. administration of $200 \mathrm{nmol}$ DL-APV, a competitive antagonist of the NMDA binding site, significantly increased T/C ratio. In this study, we selected a drug concentration and route of administration that would reliably inhibit NMDA receptor function, as evidenced by the blockade of hippocampal LTP, a physiological process linked to activation of NMDA receptors (Leung and Shen, 1999). This effect of DL-APV was consistent with previous reports implicating NMDA receptors in sensory gating (Adler et al, 1986; Miller et al, 1992a). Notably, the $\alpha$-APV-induced disruption in gating was not due to an injection artifact since the increase in T/C ratio did not occur during or immediately following $\alpha$-APV but showed a delayed onset that closely 
paralleled the latency to its effect on LTP (Leung and Shen, 1999).

Taken together, these data indicate that a near-complete inhibition of the glycine ${ }_{\mathrm{B}}$ site (using $30 \mathrm{mg} / \mathrm{kg} \mathrm{L}-701,324$ ) is without effect on $\mathrm{T} / \mathrm{C}$ ratio, whereas a total blockade of NMDA receptor activity (using $200 \mathrm{nmol}$ DL-APV) significantly attenuates auditory gating. Based on these conclusions, it is unlikely that the increase in $\mathrm{T} / \mathrm{C}$ ratio observed in $\mathrm{KYN}+\mathrm{PBCD}$-treated rats is attributable to KYNA-induced blockade of the glycine ${ }_{B}$ receptor. It is also unlikely that KYNA's disruptive effects on auditory gating are related to its ability to compete with glutamate at the NMDA recognition site or AMPA/kainate receptors since the brain levels of KYNA attained in KYN + PBCD-treated rats $(\sim 20 \mu \mathrm{M})$ remained $1-2$ orders of magnitude below its $\mathrm{IC}_{50}$ values at these sites (Stone, 2001).

It is possible that the impairment of auditory gating observed in $\mathrm{KYN}+\mathrm{PBCD}$-treated rats is related to an effect of KYNA at nonglutamatergic receptors. The recently discovered anticholinergic properties of KYNA indicate one such possibility (Hilmas et al, 2001). Cholinergic projections from the septal nucleus to the hippocampus play an important role in auditory gating (Miller and Freedman, 1993; van Luijtelaar et al, 2001), and fimbriafornix transections, which remove the cholinergic input to the hippocampus, increase the $\mathrm{T} / \mathrm{C}$ ratio in anesthetized rats (Bickford and Wear, 1995). Notably, the lesion-induced gating deficit is reversed by nicotine and probably mediated by $\alpha 7 \mathrm{nAChRs}$. This pharmacological specificity is suggested by the fact that the $\alpha 7 \mathrm{nAChR}$ antagonist $\alpha$-bungarotoxin potently disrupts auditory sensory gating while other cholinergic receptor antagonists, including mecamylamine and scopolamine, are without effect (Luntz-Leybman et al, 1992). As a noncompetitive antagonist of the $\alpha 7 \mathrm{nAChR}$ with a shallow dose-response curve ( $\mathrm{IC}_{50}: 7 \mu \mathrm{M}$, Hilmas et al, 2001), KYNA could be in a position to significantly reduce auditory gating. The concentrations of KYNA reached in the hippocampus following $\mathrm{KYN}+\mathrm{PBCD}$ treatment are certainly in a range that could be envisioned to affect $\alpha 7 \mathrm{nAChR}$ function. Importantly, however, no effect on sensory gating was seen when endogenous brain KYNA levels were raised more than 10-fold by PBCD alone. This indicates that it is possible to dissociate KYNA's antiexcitotoxic/anticonvulsant properties, which can be realized at submicromolar concentrations (Pellicciari et al, 1994; Cozzi et al, 1999; Scharfman et al, 1999), from its potentially harmful effects on cognition at much higher levels.

Finally, it should be emphasized that the increase in $\mathrm{T} / \mathrm{C}$ ratio observed in $\mathrm{KYN}+\mathrm{PBCD}$-treated animals and in rats that received DL-APV resulted from a reduction in the amplitude of the conditioning waveform, not an increase in test response amplitude. Therefore, it could be argued that these effects do not constitute an alteration in gating per se but rather a change in the animal's reactivity to the initial stimulus. While considerable effort continues to be directed toward understanding the physiological basis of auditory gating (for a review, see Leonard et al, 1996), a growing body of evidence suggests that a diminished response to conditioning stimuli may have functional and clinical importance. For example, significant reductions in conditioning response amplitude have been observed following blockade of $\alpha 7 \mathrm{nAChRs}$ (Luntz-Leybman et al, 1992). In this study, as in ours, a significant amount of the variance in $\mathrm{T} / \mathrm{C}$ ratio after drug treatment was attributed to a decrease in conditioning response amplitude. The loss of cholinergic afferents to the hippocampus following lesions of the fimbria-fornix also significantly reduces conditioning response amplitude, an effect that can be fully reversed by systemic administration of nicotine (Bickford and Wear, 1995; see above). Altered responsiveness to auditory stimuli has also been observed in humans. Thus, several laboratories have reported that the amplitude of the conditioning response is significantly reduced in schizophrenic patients (Jin et al, 1997; Patterson et al, 2000; Blumenfeld and Clementz, 2001). Moreover, in normal controls, the amplitude of the conditioning response is more tightly correlated with other indices of sensory gating (e.g. habituation and prepulse inhibition of the startle response) than T/C ratio (Schwarzkopf et al, 1993).

In summary, the results of the present study show that greatly elevated brain levels of KYNA in rats are associated with an altered responsiveness to auditory stimuli. This impairment does not appear to be attributable to the glutamate receptor antagonist properties of the compound but is likely to involve other mechanisms including an interaction with $\alpha 7 \mathrm{nAChRs}$. The recently documented increase in KYNA levels in the brain and CSF of schizophrenic patients (Erhardt et al, 2001; Schwarcz et al, 2001) could contribute to the well-characterized abnormality in sensory processing in the disease.

\section{ACKNOWLEDGEMENTS}

The authors gratefully acknowledge the technical support provided by Drs Paolo Guidetti and Hui-Qui $\mathrm{Wu}$, and $\mathrm{Ms}$ Song-Chu Lee. We are also indebted to Dr Robert McMahon for his contribution to the statistical design and analysis. This work was supported in part by a research grant from the Novartis Pharmaceutical Corporation and a grant from the National Alliance for Research on Schizophrenia and Depression.

\section{REFERENCES}

Adler LE, Freedman R, Ross RG, Olincy A, Waldo MC (1999). Elementary phenotypes in the neurobiological and genetic study of schizophrenia. Biol Psychiatry 46: 8-18.

Adler LE, Pachtman E, Franks RD, Pecevich M, Waldo MC, Freedman R (1982). Neurophysiological evidence for a defect in neuronal mechanisms involved in sensory gating in schizophrenia. Biol Psychiatry 17: 639-654.

Adler LE, Rose G, Freedman R (1986). Neurophysiological studies of sensory gating in rats: effects of amphetamine, phencyclidine, and haloperidol. Biol Psychiatry 21: 787-798.

Bickford PC, Wear KD (1995). Restoration of sensory gating of auditory evoked response by nicotine in fimbria-fornix lesioned rats. Brain Res 705: 235-240.

Birch PJ, Grossman CJ, Hayes AG (1988a). Kynurenate and FG9041 have both competitive and non-competitive antagonist actions at excitatory amino acid receptors. Eur J Pharmacol 151: 313-315.

Birch PJ, Grossman CJ, Hayes AG (1988b). Kynurenic acid antagonises responses to NMDA via an action at the strychnine-insensitive glycine receptor. Eur J Pharmacol 154: 85-87.

Blumenfeld LD, Clementz BA (2001). Response to the first stimulus determines reduced auditory evoked response suppression in 
schizophrenia: single trials analysis using MEG. Clin Neurophysiol 112: 1650-1659.

Boutros NN, Zouridakis G, Overall J (1991). Replication and extension of P50 findings in schizophrenia. Clin Electroencephalogr 22: 40-45.

Bristow LJ, Flatman KL, Hutson PH, Kulagowski JJ, Leeson PD, Young $\mathrm{L}$ et al (1996a). The atypical neuroleptic profile of the glycine/ $N$-methyl-D-aspartate receptor antagonist, L-701,324, in rodents. J Pharmacol Exp Ther 277: 578-585.

Bristow LJ, Hutson PH, Kulagowski JJ, Leeson PD, Matheson S, Murray F et al (1996b). Anticonvulsant and behavioral profile of L-701,324, a potent, orally active antagonist at the glycine modulatory site on the $N$-methyl-D-aspartate receptor complex. $J$ Pharmacol Exp Ther 279: 492-501.

Buchanan RW, Breier A, Kirkpatrick B, Ball P, Carpenter Jr WT (1998). Positive and negative symptom response to clozapine in schizophrenic patients with and without the deficit syndrome. Am J Psychiatry 155: 751-760.

Buchanan RW, Holstein C, Breier A (1994). The comparative efficacy and long-term effect of clozapine treatment on neuropsychological test performance. Biol Psychiatry 36: 717725.

Cadenhead KS, Light GA, Geyer MA, Braff DL (2000). Sensory gating deficits assessed by the P50 event-related potential in subjects with schizotypal personality disorder. Am J Psychiatry 157: 55-59.

Clementz BA, Geyer MA, Braff DL (1998a). Multiple site evaluation of P50 suppression among schizophrenia and normal comparison subjects. Schizophr Res 30: 71-80.

Clementz BA, Geyer MA, Braff DL (1998b). Poor P50 suppression among schizophrenia patients and their first-degree biological relatives. Am J Psychiatry 155: 1691-1694.

Clerkin L, Joy B, Schwarcz R, Shepard PD (2001). Elevated brain levels of kynurenic acid are associated with a disruption in auditory sensory processing. Soc Neurosci Abstr 27: 238.7.

Cozzi A, Carpenedo R, Moroni F (1999). Kynurenine hydroxylase inhibitors reduce ischemic brain damage: studies with (mnitrobenzoyl)-alanine (mNBA) and 3,4-dimethoxy-[-N-4-(nitrophenyl)thiazol-2yl]-benzenesulfonamide (Ro 61-8048) in models of focal or global brain ischemia. J Cereb Blood Flow Metab 19: 771-777.

Cullum CM, Harris JG, Waldo MC, Smernoff E, Madison A, Nagamoto HT et al (1993). Neurophysiological and neuropsychological evidence for attentional dysfunction in schizophrenia. Schizophr Res 10: 131-141.

Danysz W, Fadda E, Wroblewski JT, Costa E (1989). Kynurenate and 2-amino-5-phosphonovalerate interact with multiple binding sites of the $N$-methyl-D-aspartate-sensitive glutamate receptor domain. Neurosci Lett 96: 340-344.

Danysz W, Parsons CG (1998). Glycine and N-methyl-D-aspartate receptors: physiological significance and possible therapeutic applications. Pharmacol Rev 50: 597-631.

Erhardt S, Blennow K, Nordin C, Skogh E, Lindstrom LH, Engberg G (2001). Kynurenic acid levels are elevated in the cerebrospinal fluid of patients with schizophrenia. Neurosci Lett 313: 96-98.

Erwin RJ, Turetsky BI, Moberg P, Gur RC, Gur RE (1998). P50 abnormalities in schizophrenia: relationship to clinical and neuropsychological indices of attention. Schizophr Res 33: 157167.

Freedman R, Coon H, Myles-Worsley M, Orr-Urtreger A, Olincy A, Davis A et al (1997). Linkage of a neurophysiological deficit in schizophrenia to a chromosome 15 locus. Proc Natl Acad Sci 94: 587-592.

Fukui S, Schwarcz R, Rapoport SI, Takada Y, Smith QR (1991). Blood-brain barrier transport of kynurenines: implications for brain synthesis and metabolism. J Neurochem 56: 2007-2017.
Gramsbergen JBP, Hodgkins PS, Rassoulpour A, Turski WA, Guidetti P, Schwarcz R (1997). Brain-specific modulation of kynurenic acid synthesis in the rat. J Neurochem 69: 290-298.

Grimwood S, Kulagowski JJ, Mawer IM, Rowley M, Leeson PD, Foster AC (1995). Allosteric modulation of the glutamate site on the NMDA receptor by four novel glycine site antagonists. Eur J Pharmacol 290: 221-226.

Guidetti P, Eastman CL, Schwarcz R (1995). Metabolism of $5-{ }^{3} \mathrm{H}-$ kynurenine in the rat brain in vivo : evidence for the existence of a functional kynurenine pathway. J Neurochem 65: 2621-2632.

Guillemin GJ, Kerr SJ, Smythe GA, Smith DG, Kapoor V, Armati PJ et al (2001). Kynurenine pathway metabolism in human astrocytes: a paradox for neuronal protection. J Neurochem 78: 842-853.

Hilmas C, Pereira EF, Alkondon M, Rassoulpour A, Schwarcz R, Albuquerque EX (2001). The brain metabolite kynurenic acid inhibits alpha7 nicotinic receptor activity and increases nonalpha7 nicotinic receptor expression: physiopathological implications. J Neurosci 21: 7463-7473.

Hodgkins PS, Schwarcz R (1998). Interference with cellular energy metabolism reduces kynurenic acid formation in rat brain slices: reversal by lactate and pyruvate. Eur J Neurosci 10: 1986-1994.

Jin Y, Potkin SG, Patterson JV, Sandman CA, Hetrick WP, Bunney $\mathrm{Jr}$ WE (1997). Effects of P50 temporal variability on sensory gating in schizophrenia. Psychiatry Res 70: 71-81.

Kessler M, Terramani T, Lynch G, Baudry M (1989). A glycine site associated with $N$-methyl-D-aspartic acid receptors: characterization and identification of a new class of antagonists. $J$ Neurochem 52: 1319-1328.

Leeson PD, Iversen LL (1994). The glycine site on the NMDA receptor: structure-activity relationships and therapeutic potential. J Med Chem 37: 4053-4067.

Lehman EL (1974). Nonparametrics: Statistics Based on Ranks. Holden-Day: San Franscisco. pp 103-104.

Leonard S, Adams C, Breese CR, Adler LE, Bickford P, Byerley W et al (1996). Nicotinic receptor function in schizophrenia. Schizophr Bull 22: 431-445.

Leung LS, Shen B (1999). N-methyl-D-aspartate receptor antagonists are less effective in blocking long-term potentiation at apical than basal dendrites in hippocampal CA1 of awake rats. Hippocampus 9: 617-630.

Light GA, Braff DL (1999). Human and animal studies of schizophrenia-related gating deficits. Curr Psychiatry Rep 1: $31-40$.

Luntz-Leybman V, Bickford PC, Freedman R (1992). Cholinergic gating of response to auditory stimuli in rat hippocampus. Brain Res 587: 130-136.

Marcus R, Peritz E, Gabriel KR (1976). On closed testing procedures with special reference to ordered analysis of variance. Biometrika 63: 655-660.

McGhie A, Chapman J (1961). Disorders of attention and perception in early schizophrenia. Br J Med Psychol 34: 103-116.

Miller CL, Bickford PC, Luntz-Leybman V, Adler LE, Gerhardt GA, Freedman R (1992a). Phencyclidine and auditory sensory gating in the hippocampus of the rat. Neuropharmacology 31: 10411048.

Miller CL, Bickford PC, Wiser AK, Rose GM (1995). Long-term potentiation disrupts auditory gating in the rat hippocampus. $J$ Neurosci 15: 5820-5830.

Miller CL, Freedman R (1993). Medial septal neuron activity in relation to an auditory sensory gating paradigm. Neuroscience 55: $373-380$.

Miller JM, MacGarvey U, Beal MF (1992b). The effect of peripheral loading with kynurenine and probenecid on extracellular striatal kynurenic acid concentrations. Neurosci Lett 146: 115-118.

Miller TB, Ross CR (1976). Transport of organic cations and anions by choroid plexus. J Pharmacol Exp Ther 196: 771-777. 
Moroni F, Russi P, Lombardi G, Beni M, Carla V (1988). Presence of kynurenic acid in the mammalian brain. J Neurochem 51: 177180.

Murray F, Kennedy J, Hutson PH, Elliot J, Huscroft I, Mohnen K et al (2000). Modulation of $\left[{ }^{3} \mathrm{H}\right] \mathrm{MK}-801$ binding to NMDA receptors in vivo and in vitro. Eur J Pharmacol 397: 263-270.

Patterson JV, Jin Y, Gierczak M, Hetrick WP, Potkin S, Bunney WE et al (2000). Effects of temporal variability on P50 and the gating ratio in schizophrenia. Arch Gen Psychiatry 57: 57-64.

Paxinos G, Watson C (1986). The Rat Brain in Stereotaxic Coordinates. Academic Press: California.

Pellicciari R, Natalini B, Costantino G, Mahmoud MR, Mattoli L, Sadeghpour BM et al (1994). Modulation of the kynurenine pathway in search for new neuroprotective agents. Synthesis and preliminary evaluation of (m-nitrobenzoyl)alanine, a potent inhibitor of kynurenine-3-hydroxylase. J Med Chem 37: 647-655.

Ranck Jr JB (1973). Studies on single neurons in dorsal hippocampal formation and septum in unrestrained rats. I. Behavioral correlates and firing repertoires. Exp Neurol 41: 461-531.

Santamaria A, Rios C, Solis-Hernandez F, Ordaz-Moreno J, Gonzalez-Reynoso L, Altagracia M et al (1996). Systemic DLkynurenine and probenecid pretreatment attenuates quinolinic acid-induced neurotoxicity in rats. Neuropharmacology 35 23-28.

Scharfman HE, Hodgkins PS, Lee SC, Schwarcz R (1999). Quantitative differences in the effects of de novo produced and exogenous kynurenic acid in rat brain slices. Neurosci Lett 274: $111-114$.

Schwarcz R, Du F, Schmidt W, Turski WA, Gramsbergen JBP, Okuno E et al (1992). Kynurenic acid: a potential pathogen in brain disorders. In: Langston JW, Young A (eds). Neurotoxins and Neurodegenerative Disease, Ann NY Acad Sci, New York, Vol. 648. pp 140-153.

Schwarcz R, Pellicciari R (2002). Manipulation of brain kynurenines: glial targets, neuronal effects and clinical opportunities. $J$ Pharmacol Exp Ther 303: 1-10.

Schwarcz R, Rassoulpour A, Wu H, Medoff D, Tamminga CA, Roberts RC (2001). Increased cortical kynurenate content in schizophrenia. Biol Psychiatry 50: 521-530.
Schwarzkopf SB, Lamberti JS, Smith DA (1993). Concurrent assessment of acoustic startle and auditory P50 evoked potential measures of sensory inhibition. Biol Psychiatry 33: 815-828.

Siegel C, Waldo M, Mizner G, Adler LE, Freedman R (1984). Deficits in sensory gating in schizophrenic patients and their relatives. Evidence obtained with auditory evoked responses. Arch Gen Psychiatry 41: 607-612.

Stone TW (2001). Kynurenines in the CNS: from endogenous obscurity to therapeutic importance. Prog Neurobiol 64: 185218.

Suzuki H, Sawada Y, Sugiyama Y, Iga T, Hanano M (1987). Anion exchanger mediates benzylpenicillin transport in rat choroid plexus. J Pharmacol Exp Ther 243: 1147-1152.

Turski WA, Schwarcz R (1988). On the disposition of intrahippocampally injected kynurenic acid in the rat. Exp Brain Res 71: 563-567.

van Luijtelaar G, Fabene PF, de Bruin N, Jongema C, Ellenbroek BA, Veening JG (2001). Neural correlates of sensory gating in the rat: decreased Fos induction in the lateral septum. Brain Res Bull 54: $145-151$.

Vécsei L, Miller J, MacGarvey U, Beal MF (1992). Effects of kynurenine and probenecid on plasma and brain tissue concentrations of kynurenic acid. Neurodegeneration 1: 17-26.

Venables P (1964). Selectivity of attention in schizophrenia. In: Maher B (ed). Progress in Experimental Personality Research, Vol. 1. Academic Press: New York. pp 1-47.

Waldo MC, Carey G, Myles-Worsley M, Cawthra E, Adler LE, Nagamoto HT et al (1991). Codistribution of a sensory gating deficit and schizophrenia in multi-affected families. Psychiatry Res 39: 257-268.

Wu H-Q, Guidetti P, Goodman JH, Varasi M, Ceresoli-Borroni G, Speciale C et al (2000a). Kynurenergic manipulations influence excitatory amino acid receptor function and excitotoxic vulnerability in the rat hippocampus in vivo. Neuroscience 97: 243-251.

Wu H-Q, Lee S-C, Schwarcz R (2000b). Systemic administration of 4-chlorokynurenine prevents quinolinate neurotoxicity in the rat hippocampus. Eur J Pharmacol 390: 267-274. 